\title{
Time Series of Land subsidence rate on Coastal Demak Using GNSS CORS UDIP and DINSAR
}

\author{
B. D. Yuwono ${ }^{1 *}$, S. Subiyanto, A. S. Pratomo, Najib ${ }^{2}$ \\ ${ }^{1}$ Geodesy Department, Faculty of Engineering, Diponegoro University, Indonesia \\ 2 Geology Department, Faculty of Engineering, Diponegoro University, Indonesia
}

\begin{abstract}
Most of the studies land subsidence and impact have been done on the north coastal area of Java, especially Semarang and Demak. This landsubsidence has a very serious impact both in the infra structure, the economy and the environment. Techniques of observing landsubsidence using geodetic methods have been widely practiced. Geodetic technology is undergoing rapid development, especially in GNSS navigation satellite technology as well as satellite radar interferometry. Both have advantages and disadvantages of each. In this study will examine the application of DinSAR interferometric techniques and GNSS technology to predict the rate of land subsidence coastal of Demak regency. This paper also emphasize the role of GNSS and DinSAR application in deformation especially for landsubsidence monitoring.
\end{abstract}

\section{Introduction}

Coastal area in Sayung Demak is a very dynamic and have sufficient resource potential big, however, coastal areas are also areas that are very vulnerable to hazards such as flood and inundation land subsidence. The impact of disaster it will be more widespread if not handled properly. Rob floods have caused large loss due to inhibiting economic activity in the Regency Demak. More than 1200 houses flooded and hundreds of residents were forced relocated due to loss of settlement.[1] In this research DinSAR and GNSS measurement were conducted to indentify and analyze the trend of land subsidence.

SAR refers to the concept of RADAR using an active sensor that sends radio signals with pulses that bounce off the ground and move back to the sensor. Some of the advantages of using RADAR is that it is not limited by clouds or lack of sunlight. SAR as mentioned, a type of RADAR sensor called Synthetic Aperture Radar, which uses a synthetic antenna, made by a combination of stable data signals (Hanssen, 2001, pp. 10-11). The most effective way of monitoring ground subsidence can be conducted using dInSAR, GNSS and levelling is to first screen large areas for any movement using dInSAR. [2] The principle of interferometry is to calculate phase differences between SAR images obtained at different times. Since this phase is a measure of distance, this, in theory, represents a change in the height of a point reflected by a signal [3]. The problem of SAR image processing became more complex. The complexity is caused by different sources of error Phase comparison without any error correction will produce an inaccurate result, so the result is not realiable and unusable. Recently, different methods have been developed to exclude the error source from phase measurement and hence get much more accurate results. The application of SAR interferometry technology in this research is to monitor landsubsidence deformation. The source of phase error in SAR interferomteri is as follows, Impact of atmospheric change,The impact of orbital inconsistencies, multipath and Topography

\subsection{SAR Interferometry}

InSAR stands for SAR interferometry, the InSAR technique uses the measurement of phase change of signals (interference) between radar images. If there is a point on the surface of the earth moving there is a change in distance between the sensor and the point, it will produce the appropriate phase shift signal. The displacement in phase in the two SAR images measured at each point (pixels) is a phase difference and is known as an interferogram. The phase difference is calculated for each pixel. When InSAR is used to recognize and measure ground deformation, this process is referred to as the InSAR differential[4]. The general formation of differential Interferrograms shown in figure 1.

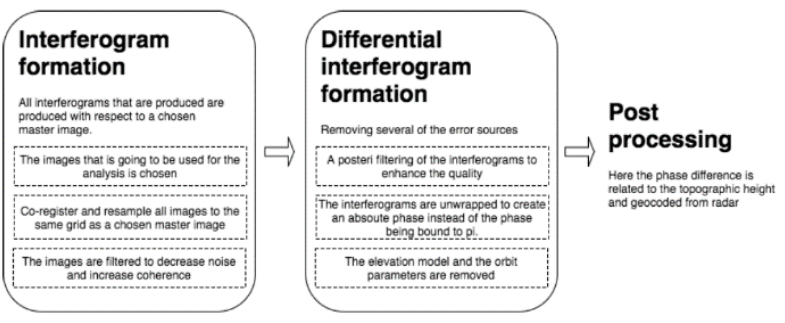

Fig. 1 General Formation of Differential Interferrograms[2]

\footnotetext{
${ }^{*}$ Corresponding author: bdyuwono92@ gmail.com
} 


\subsection{GNSS Cors}

Use of Global Navigation Satellite The GNSS system (GNSS) is increasing with accuracy reaches centimeters for relative position using the CORS station [5]. CORS applications include can be used for geoid modeling purposes (Wu et al., 2015) and for deformation purposes Dam [6].GNSS, like dInSAR, uses phase measurements from satellites. There are several types of GNSS measurements and many different systems included in GNSS terms, such as GPS, GLONASS, Galileo among others [7]

The most accurate type of measurement is the relative static position. Here there are several recipients used by being placed above the point where they are static during the session. To get a GNSS position, the receiver must get a selection to at least four different satellites, this is to get the four pseudorange data together so that it gets a $3 \mathrm{D}$ position and a clock error [7]. [8] describe in more detail about how GNSS measurements are performed in "GPS Satellite Surveys".

The GNSS CORS UDIP station was developed at the Diponegoro University Department of Geodesy in December 2012. The GNSS CORS UDIP installation is on the 3rd floor, while the server is in the laboratory Geodetic Department Measurement and Mapping,Faculty of Engineering, Diponegoro University. Installation / installation of the GNSS system [9] This CORS UDIP is based on needs survey needs, geodetic mathematical models, and digital signal processing. Description from the CORS UDIP GNSS station can be seen Figure 2.

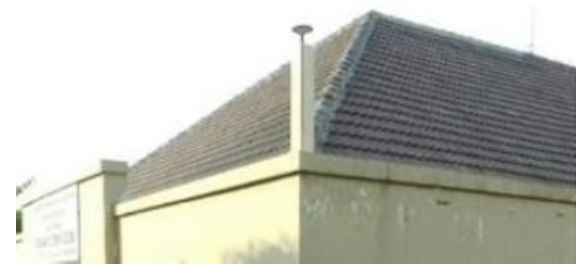

Figure 2. Station GNSS CORS UDIP

\section{Data and Method}

We have been conducted several research investigations to this area study by field observations by (mapping the landsubsidence area, pictures, conduct GPS measurement and InSAR analysis). In this research there are two pairs of images were processed in two year 2016 and 2017. In this case, the subsidence is derived using differential method, and data SRTM was used for generating the DEM for the area. In the interferogram, the phase difference is described as the distance difference measured by the line of sight (LOS) radar and includes topography, orbit shifts, surface deformation and atmospheric effects[10]. The Sentinel Data were used shown in table 1, including data acquisition, polarisation and direction scanning.
Table 1. Sentinel Data

\begin{tabular}{lccccc}
\hline No & Time Period & Level & $\begin{array}{c}\text { Acqui } \\
\text { sition } \\
\text { Mode }\end{array}$ & $\begin{array}{c}\text { Pola } \\
\text { risat } \\
\text { ion }\end{array}$ & $\begin{array}{c}\text { Direction } \\
\text { Scanning }\end{array}$ \\
\hline 1. & 14 November 2015 & 1.0 & IW & VV & Descending \\
2. & 8 November 2016 & 1.0 & IW & VV & Descending \\
3. & 24 February 2017 & 1.0 & IW & VV & Descending \\
4. & 15 November 2017 & 1.0 & IW & VV & Descending \\
\hline
\end{tabular}

The next processing, we computed differential interferograms. (Digital Elevation Model (DEM) produced from the Shuttle Radar Topography Mission with about $90 \times 90 \mathrm{~m} 2$ spacing was used to remove the phase component due to the topography of the area.. Detail master and Slave image in each year were represented at table 2 .

The GNSS data for this research of landsubsidence in Coastal Demak have been conducted on 2-8 may 2015, 23-26 april 2016,22-24 april 2017 and 7-8 may 2018. Bench Mark was installed in 6 Villages namely Sidodadi, Gemah, Tugu, Purwosari, Bedono and Timbulsloko which all of which are in the District Sayung. The GPS surveys exclusively used dual-frequency geodetic-type GPS receivers. The length of surveying sessions was in general between 6 to 7 hours. The data were observed with a 30 second interval with an elevation mask of $15^{\circ}$ The surveys of this research were mainly carried out by the staffs and students from the Department of Geodesy of Diponegoro University. GPS survey were conducted in 2018 shown in figure 3

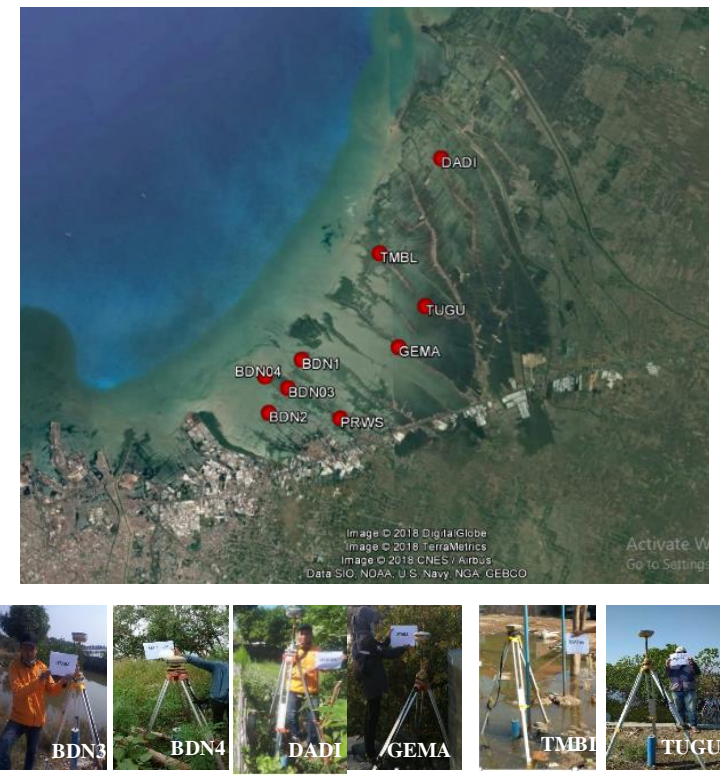

Fig 3. GPS survey 2018 ( Google Earth ) 
Table 2 Sentinel Data Aquisition

\begin{tabular}{|c|c|c|c|c|c|c|c|c|}
\hline \multicolumn{10}{|c|}{ Data Sentinel 1 Aquisition year 2016 } \\
\hline Mst/Slv & Acquisition & Track & Orbit & $\begin{array}{c}\text { Bperp } \\
(\mathrm{m})\end{array}$ & $\begin{array}{c}\text { Btemp } \\
(\text { days })\end{array}$ & $\begin{array}{c}\text { Modeled } \\
\text { Coherence }\end{array}$ & $\begin{array}{c}\text { Height } \\
\text { Ambg }(\mathrm{m})\end{array}$ & $\begin{array}{c}\text { Delta fDC } \\
(\mathrm{Hz})\end{array}$ \\
\hline Master & 14 November 2015 & 127 & 8599 & 0,00 & 0,00 & 1,00 & $\infty$ & 0,00 \\
\hline Slave & 08 November 2016 & 127 & 13849 & $-12,11$ & 360,00 & 0,66 & 1286,36 & $-1,55$ \\
\hline \multicolumn{8}{|c|}{ Data Sentinel 1 Aquisition year 2017 } \\
\hline Master & 24 Februari 2017 & 127 & 15414 & 0,00 & 0,00 & 1,00 & $\infty$ & 0,00 \\
\hline Slave & 15 November 2017 & 127 & 19274 & 32,59 & 264,00 & 0,70 & 478,27 & $-7,33$ \\
\hline
\end{tabular}

\section{Result and Discussion}

(IW) Interferometric Wide , Single Look Complex (SLC). Deformation measurement will be conducted using Sentinel-1 images. An IW SLC Sentinel-1 scene covered approximately about $250 \times 180 \mathrm{~km}$ and is consist of 3 swaths containing 9 bursts each. In this research, the DinSAR procedure is performed burst-wise over the interferograms, i.e., with a footprint of approximately $5 \mathrm{x}$ $20 \mathrm{~m}$ in range and azimuth, respectively. The PSI products are the characteristic of deformation map and the time series of the deformation spanning the period from November 2015 to November 2016 and February to November 2017. The gathered deformation map was estimated over an area of approximately $35 \mathrm{~km}^{2}$ in the northern sayung sub district, including some countryside areas. Result of Deformation DinSAR monitoring year 2015, 2016 and 2017 show figure 4.

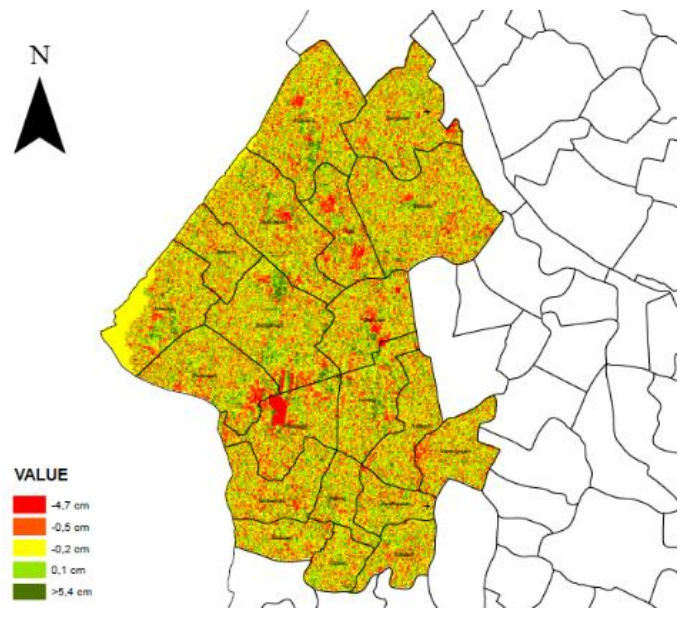

Fig 4. DinSAR 2015[11]

The further shown that land subsidence affects north parts of Sayung. This is particularly true for the northwestern districts of the city and situated north of the boundary at alluvial sediments. In the northern portion of the researched area, single points characterized by rapid subsidence are probably connected to tidal flood but have still to be checked in the field.

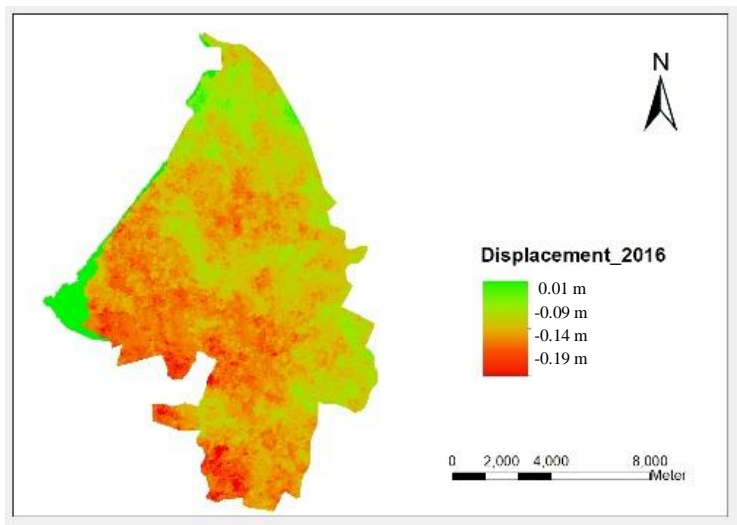

Fig 4. DinSAR 2016

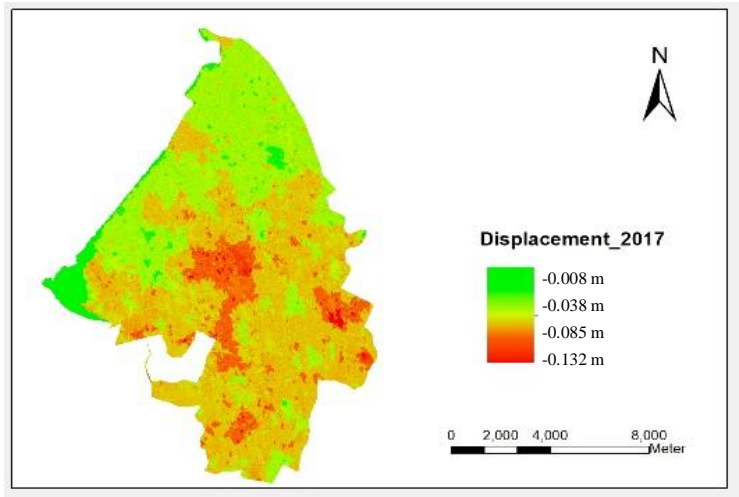

Fig 5 DinSAR 2017

Figure 4 and 5 shown widespread fringe patterns related to the slow deformation with a time lag of three years. The two interferometric methods determined similar results with small differences. The deformation fringes are to be verified in a future research article by advanced multitemporal DInSAR, and next research must be used by precise levelling measurements. Results from DInSAR processing shown in Figure 4 shown sayung district tend to subsided with a max value of $4.7 . \mathrm{cm}$. The magnitude of the decline varies in every region of In Figure 4 shown the Phase unwrapping data, the next step is to change the phase to shift to determine the Los quantity. The result of the phase change process to the landsubsidece. DInSAR processing shown in Figure 5 show sayung district tend to subsided with a max value of $19.5 \mathrm{~cm}$ in 2016 . Figure 5. 
DInSAR Sayung district. DinSAR ocessing year 2017 show sayung district having trend landsubsidence value of $13.2 \mathrm{~cm}$. The magnitude of the landsubsidence found in the middle of sayung district. Rekapitulation of min max value using DinSAR Processing in year 2016 - 2017 shown in table 3

Table 3 DinSAR Processing

\begin{tabular}{llcccr}
\hline Year & Sub District & Max & Min & Average & StdDevv \\
\hline 2016 & Sayung & $-0,195$ & 0,010 & $-0,093$ & 0,031 \\
2017 & Sayung & $-0,132$ & 0,055 & $-0,047$ & 0,021 \\
\hline
\end{tabular}

The gps data were processed using the GAMIT 10.6 [12]. The GPS data processing strategy uses CORS UDIP and UDIP9 IGS stations consisting of BAKO, CNMR, COCO, DARW,IISC,KAT1,PIMO,SOLO and XMIS. Several output file results such as h-files, summary files, and Q-file Gfiles, T-files, X-files, J-files, D-files, K-files, $\mathrm{B}$-files from output results processing on gamit contains the most important files like h-files.

The result of gps data processing in 2018, there was postfit value $<0.5$. from the results of these observations shows the existence of a fairly small cycle slips. The Wide lane value can be said to be very good because the WL value in the table above shows $>90 \%$. Whereas the value of Narrow Lane can be said to be quite good because more show results $>80 \%$ where for NL values it is said to be good if $>80 \%$ for NL values that are $<80 \%$ because of errors such as error in size, orbital errors and bad conditions atmosphere. Postfit nrms shonw in table 4.

Table 4 Posfit nrms and Phase Ambiquity 2018

\begin{tabular}{|c|c|c|c|c|c|c|c|c|c|c|c|c|c|c|}
\hline \multirow{3}{*}{ Point } & \multirow{3}{*}{ DOY } & \multicolumn{4}{|c|}{ Postfit nrms } & \multirow{2}{*}{\multicolumn{2}{|c|}{ Ambiquity }} & \multirow{3}{*}{$\begin{array}{l}\text { PRWS } \\
\text { WNSR } \\
\text { SIDO }\end{array}$} & \multirow{3}{*}{$\begin{array}{c}-4,13 \\
-8,09 \\
-11,88\end{array}$} & \multirow{3}{*}{$\begin{array}{l}-4,11 \\
-5,56 \\
-8,17\end{array}$} & \multirow[t]{3}{*}{$-10,98$} & \multirow[t]{3}{*}{$-10,92$} & \multirow{3}{*}{-16.75} & \\
\hline & & \multicolumn{2}{|c|}{ Constrained } & \multicolumn{2}{|c|}{ Loose } & & & & & & & & & \\
\hline & & Free & Fix & Free & Fix & $\begin{array}{c}\text { WL } \\
\%\end{array}$ & NL \% & & & & & & & \\
\hline PRWS & 128 & 0,18 & 0,18 & 0,177 & 0,180 & 89,9 & 65,7 & GEMA & $-12,26$ & $-12,16$ & 0,52 & 0,52 & $-17,2$ & $-17,91$ \\
\hline GEMA & 127 & 0,18 & 0,19 & 0,179 & 0,183 & 88,2 & 77,7 & TUGU & $-6,53$ & $-6,49$ & $-0,85$ & $-0,85$ & $-9,97$ & $-10,35$ \\
\hline TUGU & 127 & 0,18 & 0,18 & 0,178 & 0,183 & 86,9 & 76,1 & TMBL & $-11,74$ & $-11,68$ & $-4,77$ & $-4,74$ & $-5,17$ & $-5,37$ \\
\hline TMBL & 127 & 0,18 & 0,19 & 0,180 & 0,184 & 87,9 & 68,3 & SURO & 0,32 & 0,22 & & & & \\
\hline DADI & 127 & 0,18 & 0,19 & 0,179 & 0,183 & 82,2 & 77,7 & DADI & 2,62 & 2,60 & $-2,79$ & $-2,77$ & $-12,87$ & $-13,36$ \\
\hline BDN1 & 128 & 0,18 & 0,18 & 0,176 & 0,180 & 89,3 & 65,7 & BDN1 & & & $-11,88$ & $-11,78$ & & \\
\hline BDN2 & 128 & 0,18 & 0,18 & 0,176 & 0,180 & 88,5 & 65,6 & BDN2 & & & & & $-16,24$ & $-16,86$ \\
\hline BDN3 & 128 & 0,18 & 0,18 & 0,177 & 0,181 & 87,8 & 67,8 & BDN3 & & & & & $-12,7$ & $-13,26$ \\
\hline BDN4 & 128 & 0,18 & 0,18 & 0,179 & 0,183 & 90,6 & 70,6 & BDN4 & & & & & $-4,06$ & $-4,24$ \\
\hline
\end{tabular}

GLRED / GLOBK processing can be done after the GAMIT process that produces $h$-files which is the main requirement in processing GLOBK. The results obtained from this processing are $3 \mathrm{D}$ cartesian coordinates $(\mathrm{X}, \mathrm{Y}$, $\mathrm{Z}$ ) and topocentric coordinates $(\mathrm{N}, \mathrm{E}, \mathrm{U})$ with their respective deviation. To obtain the height value obtained from the difference between two high values of different epoch observations. List of topografi coordinat in 2018 can be seen in table 5

The standard deviations of GPS-derived relative ellipsoidal heights in 2018 from all surveys were in general better than $3 \mathrm{~mm}-4 \mathrm{~cm}$ (see at Table 5). A few points have slightly larger standard deviations, due to the lack of observed data caused by the signal obstruction

Table 5 Coordinate Topocentric and Standart Dev 2018

\begin{tabular}{|c|c|c|c|c|c|c|}
\hline Stn & $\mathbf{n}$ & $\mathbf{e}$ & $\mathbf{u}$ & $\mathbf{m m}$ & $\mathbf{m m}$ & $\mathbf{m m}$ \\
\hline GMA & $-770112,787$ & 12212867,626 & 27,18 & 4,32 & 5,99 & 18,99 \\
\hline DDI & $-764693,243$ & 12215442,674 & 27,37 & 5,37 & 7,62 & 26,24 \\
\hline TBL & $-767399,065$ & 12213032,940 & 27,06 & 6,14 & 8,88 & 29,32 \\
\hline TGU & $-768940,718$ & 12213954,998 & 27,45 & 3,83 & 5,58 & 15,16 \\
\hline BN1 & $-770421,731$ & 12209994,759 & 28,53 & 4,54 & 6,35 & 18,71 \\
\hline BN2 & $-771935,836$ & 12208725,913 & 28,59 & 4,62 & 6,45 & 19,21 \\
\hline PWS & $-772129,102$ & 12210705,244 & 28,42 & 4,56 & 6,5 & 20,18 \\
\hline BN4 & $-770887,092$ & 12208852,755 & 27,93 & 5,75 & 7,4 & 30,23 \\
\hline BN3 & $-771235,042$ & 12209436,770 & 27,40 & 4,98 & 7,01 & 23,54 \\
\hline
\end{tabular}

Analysis of Land Deformation period 2015-20108 period in the coastal area can be seen in Table 6. Results from GPS survye show that vertical displacement in Demak has spatial variations, ranging from 0.8 to $17,91 \mathrm{~cm} /$ year (see Table 6 and Figures 5). Midle region of Sayung district exhibits higher rates of subsidence compare to northern and southern region,

Table 6 Time Series of Landsubsidence

2015-2016 2016-2017

2017-2018

Several monitoring stations such as PWS, WNSR, SIDO, SURO, BDN1 was broken due to unstable due to road works / construction and even widening of the road. So It have to be installed in new location The new station is on BDN3 and BDN4.

Time series results shown that there is an increasing trend of land subsidence in the PRWS location. Whereas in the GEMA, TMBL, TUGU locations there were a variation in land subsidence in each year with different land subsidence rate of deformation. 


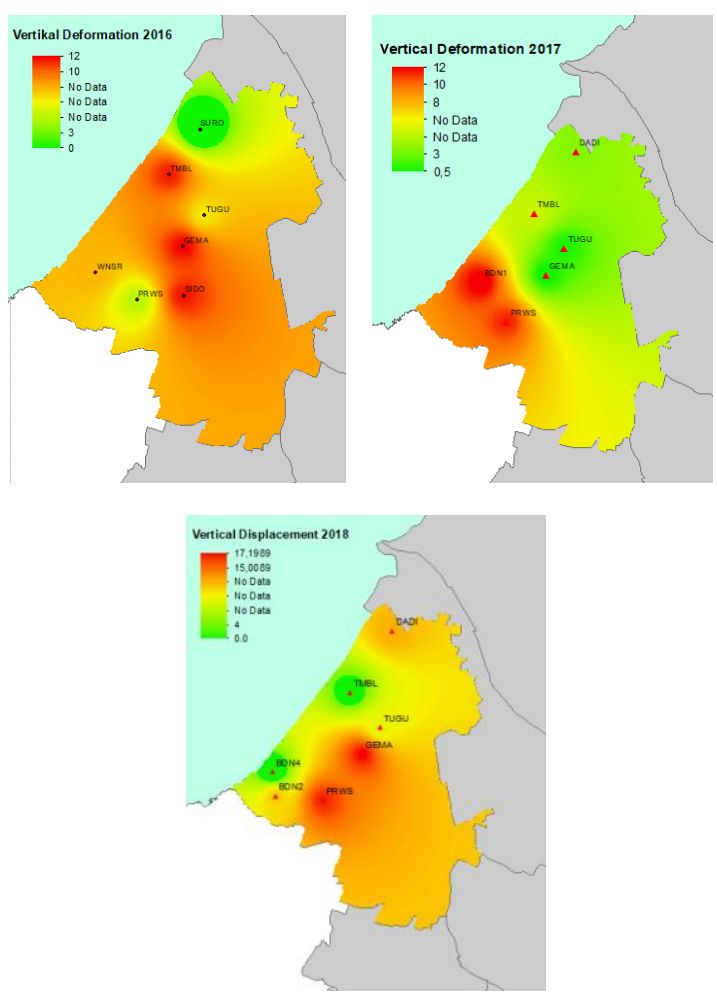

. Fig 5 Land subsidence derived GPS survey 2015-2018

Mostly, the subsidence derived by two methods can be shown in table 6 extremly cannot be compared since it has quite different temporal and spasial coverage. The table show land subsidence interval observation from 2015 to 2018 , while interval of observation land subsidence for DinSAR from 2016 to 2017.

Table 6 Trend of Landsubsidence

\begin{tabular}{|l|l|l|l|l|}
\hline \multirow{2}{*}{ Titik } & \multicolumn{2}{|c|}{ GNSS } & \multicolumn{2}{c|}{ DinSAR } \\
\cline { 2 - 5 } & $\begin{array}{l}\text { h16-17 } \\
(\mathbf{c m})\end{array}$ & $\begin{array}{l}\text { h17-18 } \\
(\mathbf{c m})\end{array}$ & $\begin{array}{l}\text { h16 } \\
(\mathbf{c m})\end{array}$ & $\begin{array}{l}\mathbf{h 1 7} \\
(\mathbf{c m})\end{array}$ \\
\hline PRWS & $-10,98$ & 16,75 & $-11,40$ & $-5,10$ \\
\hline WNSR & & & $-9,97$ & $-5,10$ \\
\hline SIDO & & & $-10,77$ & $-5,36$ \\
\hline GEMA & -0.52 & $-17,20$ & $-10,45$ & $-3,29$ \\
\hline TUGU & $-0,85$ & $-9,97$ & $-10,27$ & $-6,35$ \\
\hline TMBL & $-4,77$ & $-5,17$ & $-9,63$ & $-3,21$ \\
\hline SURO & & & $-6,89$ & $-6,00$ \\
\hline DADI & $-2,79$ & $-12,87$ & $-8,94$ & $-2,36$ \\
\hline BDN1 & $-11,88$ & & $-12,56$ & $-0,55$ \\
\hline BDN2 & & $-16,24$ & $-13,47$ & $-1,36$ \\
\hline BDNO & & & $-13,31$ & $-5,60$ \\
\hline BDN3 & & $-12,02$ & $-11,20$ & $-5,90$ \\
\hline BDN4 & & $-4,06$ & $-9,60$ & $-5,40$ \\
\hline
\end{tabular}

\section{Closing Remark}

One of the weakness of DinSAR Processing, is that the coherence is still quite low, this is due to temporal decorrelation, so there is quite a lot of data with adjacent temporal and baseline distances. For temporal distance data acquisition can be done every 6 months with a baseline distance $=150 \mathrm{~m}$. From the results shown there are still have low coherence due to temporal, atmospheric and noise decorrelation, it is necessary to increase the accuracy using the PS InSAR technique.

In this study we propose, It should be installed a stable BM for a long time and validate the DInSAR and GNSS analysis with leveling measurements, which aim to improve understanding of the characteristics of the geohazard process and enable a good correlation between methods.

\section{Aknowledgment}

This research was financially supported by Diponegoro, Indonesia through Riset Pengembangan dan Penerapan Grant 2018.

Special thanks to PT Adhi Mulia Interniagatama who installed GNSS CORS UDIP.

\section{References}

[1] Suryanti W A and Marfai A 2016 Analisis Multibahaya di Wilayah Pesisir Kabupaten Demak J. BUMI Indones. 5, Nomor 2

[2] Östblom E 2017 Possibilities to make measurements of ground subsidence more effective , using dInSAR, GNSS and levelling

[3] Ferretti A, Prati C and Rocca F 2001 Permanent Scatterers in SAR Interferometry 39 8-20

[4] Ishwar S G and Kumar D 2017 Application of DInSAR in mine surface subsidence monitoring and prediction 112

[5] Haasdyk J, Roberts C and Janssen V 2010 Automated Monitoring of CORSnet-NSW using the Bernese Software Automated Monitoring of CORSnet-NSW using the Bernese Software 11-6

[6] Yuwono B D, Awaluddin M and Yusuf M A 2017 Geodetic Deformation Monitoring at Pendidikan Diponegoro Dam 040001

[7] Hofmann-Wellenhof 2008 GNSS (SpringerWienNewYork)

[8] Alfred Leick, Lev Rapoport and Tatarnikov D GPS Satellite Surveying (Wiley)

[9] Yuwono B D, Awaluddin M and Widi H 2017 ANALISIS KECEPATAN PERGERAKAN STATION GNSS CORS UDIP ( Velocity Rate Analysis GNSS Station CORS UDIP ) J. Ilm. Geomatika 23 No.1 Me 27-36

[10] Castañeda C, Pourthié N and Souyris J C 2011 Dedicated SAR interferometric analysis to detect subtle deformation in evaporite areas around Zaragoza, NE Spain Int. J. Remote Sens. 32 186184

[11] Yuwono B D, Prasetyo Y and Islama L J F 2018 Investigation of Potential Landsubsidence using GNSS CORS UDIP and DinSAR, Sayung, Demak, Indonesia IOP Conf. Ser. Earth Environ. Sci. 123 19

[12] Yuwono B D, Abidin H Z, Gumilar I, Andreas H, Awaluddin M, Haqqi K F and Khoirunisa R 2016 Preliminary survey and performance of land subsidence in North Semarang Demak AIP Conf. Proc. 1730 1-12 